\title{
Constraints in the Management of Teachers' Continuing Professional Development for Curriculum Reform Implementation in South Africa
}

\author{
Thabo Phorabatho \\ Department of Education, North-West Province \\ Email: thabophorabatho@nwpg.gov.za \\ Patrick Mafora \\ Department of Educational Leadership and Management, University of South Africa \\ Email:pmafora@unisa.ac.za
}

Doi:10.5901/mjss.2013.v4n13p617

\begin{abstract}
This article reports selected findings from a larger qualitative study which explored how curriculum coordinators and school management teams managed teachers' continuing professional development for curriculum reform implementation. Respondents were purposively sampled from education area offices and secondary schools in the North-West Province in South Africa. Data were collected through interviews and document analysis and analysis thereof followed Tesch's open coding method. Findings suggest that teachers' continuing professional development is ineffectively managed. Some flawed management practices and systemic barriers that emerged as underlying infective management are outlined. Pertinent recommendations are made.
\end{abstract}

Keywords: curriculum change, continuing professional development, educational management, teachers, South Africa

\section{Introduction}

The school curriculum reform has become one of the key features of educational reforms in post-apartheid South Africa. In terms of the White Paper on Education and Training (Republic of South Africa, 1995), which served as the framework for the development of new curricula, Outcomes-Based Education (OBE) was designated as the new mode for curriculum delivery. It underpinned the following curricular that were introduced in rapid succession: Curriculum 2005 in 1998; the Revised National Curriculum Statement in 2004; and the National Curriculum Statement in 2006. This introduction of OBE impacted directly upon pedagogical practices in the classroom. Teachers were required to move away from rote-learning, subject-bound, content-laden approach of the past apartheid education system (Department of Education, 2001) to a new leaner-centred and outcomes-driven methodology. This paradigm shift required high-quality continuing professional development (CPD) of teachers to facilitate the delivery of the new curriculum. This became even more important given that the majority of South African teachers had received inferior schooling and basic teachers' training during the apartheid era (Day \& Sachs, 2004; Lemmer \& Badenhorst, 1997). Unfortunately, in spite of this need, curriculum reform implementation had seldom been complemented with quality teachers' CPD initiatives.

Programmes and activities that were meant to provide teachers with the necessary knowledge, skills and attitude for the effective implementation of curriculum change were, in the main, found inadequate (Steyn, 2010; Ono \& Ferreira, 2010; Phorabatho, 2010). Some limitations identified in the Report of the Task Team for the Review of the Implementation of the National Curriculum Statement were that several CPD initiatives were irrelevant to the actual professional development needs of teachers, and lacked follow-up through classroom-based monitoring, mentoring and support (Department of Basic Education, 2009). Fraught with such limitations, these teachers' CPD programmes could not possibly facilitate effective curriculum change implementation. Against this background, it was deemed necessary to investigate management practices of curriculum coordinators and school management teams with regard to teachers' $\mathrm{CPD}$ in one province in South Africa. To this end, the key questions which this article seeks to address are:

- What constitutes the role of curriculum coordinators and SMTs in managing teachers' CPD for curriculum change implementation?

- How do curriculum coordinators and SMTs perceive their role of managing teachers' CPD for curriculum 
change implementation?

- Which barriers and limitations are inherent in the management of teachers' CPD for curriculum change implementation?

\section{Literature Review}

The management of teachers' CPD for curriculum change implementation is the responsibility of the relevant authorities at the different administrative levels of the education system (Prinsloo, 2008; Department of Education, 2007). In the North-West province in South Africa, this is the responsibility of curriculum coordinators and SMTs at Area Office (AO) and school levels, respectively. The following include some of the significant duties and responsibilities of curriculum coordinators and SMTs as managers of teachers' CPD for curriculum change implementation:

\subsection{Generating a positive organisational climate for the implementation of teachers' CPD}

Tanner and Rehage (1988) aver that any attempt sought to manage teachers' CPD for curriculum change implementation independent of changing some basic organisational features runs the risk of partial or complete failure. As leaders, CPD managers are responsible for orchestrating an organisational climate that engenders, rather than militates against teachers' CPD for curriculum change implementation (Mafora \& Phorabatho, 2011; Darling-Hammond \& McLaughlin, 1995). Key features of such an environment would include, among others: facilitating change, promoting teamwork, decentralised power, effective resources utilisation, cohesiveness, adaptation and sound morale (Bitzer in Munonde, 2007; Darling-Hammond \& McLaughlin, 1995). To create such an ideal organisational climate, curriculum coordinators and SMTs should commence with transformation of organisational culture (Smit et al, 2011; Sallis, 2008). They should promote teachers' access to relevant CPD opportunities (Ha, Lee, Chan \& Sum, 2004; Bubb \& Earley, 2007), and also apply a participative management approach. This may lead to heightened teachers' morale (Mafora \& Phorabatho, 2011), ignite and sustain their senses of ownership, commitment and cooperation in a sustainable and accountable manner (Nkabinde, 2006; Coleman, 2005).

\subsection{Providing sound planning}

Planning is a management task that entails forward thinking as it reflects where the organisation aspires to be in future (Lourens, 2012). A common view (Smit et al, 2011; Van Deventer, 2008a) is that when planning for teachers' CPD for curriculum change implementation, curriculum coordinators should attempt to answer the following related questions beforehand:

- What are the development needs of individual teachers and schools regarding curriculum change implementation?

- How are the identified needs going to be addressed?

- When and where will the needs be addressed?

- Who will be responsible and what resources will be required? and,

- How is the plan going to be implemented?

In accordance with the above key questions, Mafora and Phorabatho (2013) maintain that planning for teachers' curriculum change implementation should be a contexualised process through which the unique circumstances of the individual organisation are addressed.

\subsection{Organising CPD facilitating structures}

Organising involves creating organisational structures that enable people to work together effectively towards achieving the organisation's planned objectives through the best utilisation of resources (Lourens, 2012; Smit et al, 2011; Lussier, 2009). Invariably, poor planning results in ineffective implementation of plans. Van Deventer (2008) and Steyn (1999) suggest that when organising, CPD managers should, among other critical aspects, form steering committees, establish CPD-linked organisational structure, delegate certain functions and, coordinate relevant activities in order to effectively put the programme into action. 


\subsection{Leading the implementation process}

Glover and Law (2004) assert that leading is a management function that is concerned with the ways in which intended plans are operationalised. This requires that CPD managers should inspire, influence and motivate others to work together and willingly accomplish set goals and objectives (Lourens, 2012; Smit et al., 2011; Mosoge, 2008). In order to elicit the above behavioural responses from their subordinates, Prinsloo (2008) suggests CPD managers should be able to communicate and motivate their subordinates effectively.

\subsection{Controlling the implemented plans to determine organisational success}

Controlling entails ascertaining the level of success in implementing a strategy by comparing the actual performance against the predetermined goals set during the planning phase (Hill \& McShane, 2008; Bubb \& Earley, 2007; Tomlinson, 2004). The controlling function enables CPD managers to determine what went well and what was less successful during or after the implementation of the plans (Tranter, 2006). An effective control system serves as a decision point regarding the plans. Plans are retained, adjusted, or revised. With regard to managing teachers' CPD for curriculum change implementation, curriculum coordinators and SMTs are expected to develop and implement continuous controlling measures to ascertain the extent to which the objectives of CPD programmes materialise. This may allow CPD managers to detect and determine early warnings of challenges that can hamper the effectiveness of the CPD initiatives. It may also enable them to generate possible solutions to perceived problems. CPD managers may also be able to recognise strong points of the CPD programmes that need to be retained and strengthened. Swanepoel (2009), Van Deventer (2008b) and Smit et al (2011) concur on a sequence of four interconnected steps which are worth considering as guidelines for controlling. These are: establishing standards for measuring performance, measuring the actual performance, comparing actual performance against set standards, and applying corrective measures.

\section{Research Methodology}

A qualitative case study approach was used to answer the research questions from the participants' perspective (Lichtman, 2013; Creswell, 2009).

\subsection{The sample}

The sample comprised of four Further Education and Training (FET) curriculum coordinators, eight FET subject advisors, SMT members from twenty-four secondary schools comprising of one principal, a Head of Department (HoDs), and an entry level teacher per school. Data from teachers is excluded from this article. The sample was drawn from purposively selected schools and Area Offices falling under the administration of the North West Education Department (NWED). The sample was carefully hand-picked on the basis of their presumed special knowledge of the subject under investigation and their willingness to share such with the researcher (MacMillan \& Schumacher, 2010; Creswell, 2009).

\subsection{Data collection}

In addition to literature review data were collected through document analysis and in-depth semi-structured individual and focus-group interviews. For a verbatim account, interviews were tape-recorded with the participants' prior consent. This provided material for reliability checks (McMillan \& Schumacher, 2010), and for checks against bias or misinterpretation (Opie, 2004). Similarly, note-taking helped with reformulation of interview questions and probes, and to record non-verbal communication which facilitated data analysis (McMillan \& Schumacher, 2010). Interview data were also verified, corroborated and augmented by examining documents pertinent to teachers' CPD for curriculum change implementation (Yin, 2009:103).

\subsection{Data analysis}

Data were analysed through Tesch's open coding method (Creswell, 2009). This approach involved an inductive process of examining, selecting, categorising, comparing, synthesising and interpreting data for credible explanations to address the central aim of the study (McMillan \& Schumacher, 2010). 


\subsection{Ethical considerations}

In addition to ethical clearance from the University of South Africa, permission to conduct the study was obtained from the North-West Provincial Department of Education and individual respondents. The latter's participation was free and voluntary and they were guaranteed anonymity and confidentiality. Hence only pseudonyms are used and not participants' real names (Schulze, 2002). All information presented by the participants and data derived from examined documents was subjected to strictest confidentiality. Mason (in Thwala, 2010) states that documents should take a private or confidential form because they are likely to refer to or implicate people other than their owners or keepers. The findings for each of the abovementioned research questions are presented below.

\section{Discussion of findings}

Data analysis yielded two broad themes which are discussed in detail together with their respective sub-themes below:

- Limited understanding of the management function in teachers' CPD for curriculum change implementation; and

- Systemic barriers to effective management of teachers' curriculum-related CPD

\subsection{Limited understanding of the management function in teachers' CPD}

Respondents' descriptions of how they discharge their functions suggest that the majority lack a proper conception of what constitutes their role. Some respondents even conceded that they are not aware that they are expected to follow formal management processes in a quest to improve the quality of teachers' CPD. Emergent sub-themes in this regard included: 1) Inadequate modification of organisational climate; 2) ineffective teachers' CPD needs assessment; 3 ) inadequate organising; 4) ineffective communication and lack of motivation; and, 5) poor controlling of activities pertinent to teachers' CPD.

\subsubsection{Inadequate modification of organisational climate}

Findings suggest that the majority of participants are aware that a favourable environment is one of the preconditions for effective teachers' curriculum change-related CPD, and that it is their responsibility to create such environment in their AOs and schools. They, however, conceded that their practices, in the main, have the opposite effect. Responses suggest that decision-making around training are typically unilateral, authoritative and imposed without the input of affected stakeholders. Some informative comments in this regard were:

What they decide there we have to implement without questioning (Subject Advisor).

It seems as if the people up there do not take us seriously. When they plan the workshops they don't consult us. We only receive notices in the form of circular or SMS [mobile-phone text messages]. Usually the notices are sent within very short space of time and they are frustrating (Principal L2-MOR).

Where professionals expect to be heard but feel silenced and marginalised, they tend to become demoralised and resistance-prone. Logically, this would undermine the goals of teachers' CPD. Besides, exclusionary practices contradict the stance of the Department of Education (2000) that education managers should adopt democratic and participative management systems to build relationships with stakeholders in order to elicit smooth implementation of current policies.

Data analysis also points to CPD managers being unable to create an environment that is conducive to learning by making the required resources and facilities available. All respondents expressed the view that training venues are usually inaccessible through public transport, decrepit, fraught with destructions, and lacked basic facilities like water, electricity and sanitation. Our contention is that, instead of facilitating teachers' reception and conception of the new curriculum meant to be discussed in such training these conditions are more likely to elicit teachers' negativity and resistance to CPD initiatives, not just the venues. This will further militate against the goals of CPD and the effect becomes manifest at classroom level.

\subsubsection{Ineffective teachers' CPD needs assessment}

It emerged from data analysis that the majority of participants are aware that teachers' CPD should help address their 
professional development needs. Interestingly, however, none of them explicitly related the activity of assessing teachers' CPD needs to their own roles as CPD managers. It is disturbing that the majority of sampled schools seldom organised their own CPD programmes, and that most of the CPD initiatives provided at AOs were planned by external bodies and structures linked to either the national or provincial levels of the Department of Basic Education. Such training initiatives are based on teachers' needs that are identified through an instrument with limited validity and reliability learner performance in Grade 12 examinations. This contradicts the official position that teachers' needs for continuous professional development should be based on the outcomes of the Developmental Appraisal process (Letlhoo, 2011; Education Labour Relations Council, 2003; Blandford, 2000). A respondent's lamentation in this regard was:

We operate on the basis of analysis of results (matric). Now, when results are analysed, there is what we call item analysis by subject-specific analytical moderators at marking centres. Where learners perform poorly, it means a teacher is not competent with that area of the works schedule (Subject advisor 1-BOJ).

Basing teachers' professional development needs solely on matric results is limited and inappropriate in that it is premised solely on deficiency theory, excludes the needs of teachers in other grades, does not consider teachers' inputs and, ignores other contextual factors regarding the implementation of curriculum change.

\subsubsection{Inadequate organising}

All participants displayed scant understanding of what the function of organising involves. For the majority, "organising" meant the allocation of physical and material resources only. They did not mention other important activities such as departmentation, establishment of organisational structures, delegation and coordination. This suggests that not all processes in the organising phase are followed. Analysis of responses suggests that CPD managers monopolise their role in that there are no structures or committees formed to oversee teachers' CPD for curriculum change implementation in all the selected AOs. Conversely, the study found that the Staff Development Teams (SDTs), formed in accordance with the Developmental Appraisal policy (IQMS), were not active and ineffective in the majority of the sampled schools. Revealing responses in this regard were:

When we organise, we just look at the dates and the right venue. About the resources, it is every man for himself...(Subject advisor 1-MOR)

Oh no... we do not have such committees at our AO. I don't know about other AOs. I haven't heard any of my colleagues talking about it. But l'll check. You know we operate under the assumption that such committees should prevail in schools only...it is a great idea (Curriculum coordinator-2)

CPD managers that do not organise effectively and those who centralise their role run a risk of becoming ineffective as a result of increasing workload, lack of cooperation and resistance on the part of their subordinates. It is highly unlikely that the goals of teachers' CPD for curriculum change implementation would be achieved under such conditions.

\subsubsection{Ineffective communication media}

There was consensus among the participants that in order to be successful in their role, CPD managers should be efficient and effective communicators. Document analysis and interview data revealed that CPD managers communicated through notices, in the form of circulars, notifying the teachers to attend CPD activities organised at the different AOs. A number of participants also disclosed that CPD managers also sent notices through mobile phone text messages. Nonetheless, most participants felt that the ways in which CPD managers communicated were inadequate. The majority of principals and HoDs mentioned that they found the excessive use of sending notices via the medium of mobile text messages irritating and undermining. They also expressed dissatisfactions regarding the short notices that they were often given for training initiatives. One such comment was:

The workshops are organised haphazardly. This causes a lot of disruption to the free-flow of teaching and learning in our schools. At least if they can call principals to a meeting [to get their inputs] or send the notices in advance it will be better. We will know and make proper arrangements beforehand (HoD T1-DIT). 
CPD managers who fail to communicate effectively are likely to demoralise their subordinates who miss or lose critical CPD opportunities due to poor communication and consequently damage interpersonal relations.

\title{
4.1.5 Poor control of activities pertinent to teachers' CPD
}

In all interviews the participants emphasised controlling as the evaluation of the quality of the training workshops. However, some inconsistencies in their narrated practices were noted. There was no common phase for evaluation. It was conducted immediately after the training workshops; during normal school visits; or it was completely ignored. The study also found that subject advisors used different evaluation instruments and that the results of the evaluation were not given the necessary attention at any level of the education system. Ironically, several subject advisors felt that the evaluation exercise was not worth the efforts. Some developed alternative methods to assess the effectiveness of the workshops, and others had totally stopped the evaluation exercise. Some of the informative remarks were:

\begin{abstract}
At the end of the workshop teachers are given questionnaires for evaluation of the workshop. In my view, I don't think they were telling the truth, they will simply tell you that they have enjoyed the workshop, they have gained a lot but in reality the same feedback they are giving us, is not the same as the feedback they giving their unions (Subject advisor $1-M A H)$.
\end{abstract}

Before I used to give them evaluation forms but these days I count on their [verbal] responses. Usually at the end of the session I would have a session where they give comments or appreciations (Subject advisor 1-DIT).

Inadequate control systems may have major quality implications for future teachers' CPD for curriculum change implementation training workshops and other related interventions. Essentially, poor controlling of the provided CPD programmes or lack thereof deprives the planners of proper feedback to determine the success or otherwise of the provided training. This flaw, if not adequately addressed, is likely to subject future CPD initiatives to the same degree of inadequacy or failure as their predecessors (Steyn, 2010; Ono \& Ferreira, 2010; Duthilleul, 2005). In this way, it has potential to continue the teachers' ineffectiveness in implementing curriculum change. The CPD managers' limited understanding was exacerbated by the practical barriers they experienced when discharging their role.

\subsection{Systemic barriers to effective management of teachers' curriculum-related CPD}

The empirical investigation revealed that the sampled CPD managers faced a litany of barriers that impaired their effectiveness. These challenges and their implications on the role of CPD managers are outlined below.

\subsubsection{Limited training of CPD managers}

The empirical data evinced that the majority of the CPD managers were not sufficiently trained to manage teachers' CPD for curriculum change implementation. This corresponds with other studies (Mafora and Phorabatho, 2011; Mizell, 2010; Mulkeen et al.,2005) that pointed to education managers often being marginalised and not receiving specific training and development related to the task of managing curriculum change implementation. One principal remarked thus:

\begin{abstract}
Ahh, no. I've been a principal in this area office since 2001. I have never attended any training or meeting where we were guided on how to manage the introduction of OBE, not to mention teacher development. That [managing teacher's $C P D]$, I don't think there is anyone at the area office who can train us about it. They should start by training us about how to manage the new curriculum first (Principal A2-DIT).
\end{abstract}

Without proper training, CPD managers may find it extremely difficult to execute their duties and responsibilities meaningfully. Similarly, the majority of participants indicated that the lack of adequate training fed into a web of other hindrances. These included: role ambiguity and lack of role ownership, ignorance about the policies that guide teachers' CPD, inadequate management of the implementation of teachers' Developmental Appraisal and, lack of school-based teachers' CPD initiatives for curriculum change implementation.

\subsubsection{Shortage of relevant resources}

The participants were unanimous that lack of relevant resources is another main impediment to the effectiveness of their 
role as CPD managers. Specifically, the sampled AOs and schools identified challenges with regard to the following CPD-related resources: suitable accommodation, and relevant instructional aids and official means of transport. Typically, training venues posed threats to the CPD quality as they, among other limitations, were difficult to access especially on public transport; fraught with distraction; lacked basic facilities such as water, power and sanitation; and, had insufficient sitting accommodation for the number of teachers attending the training workshops. Conco (2004) also discovered that the condition under which the teachers were offered training workshops for curriculum change implementation was non-conducive, as the teachers were crammed into a small lecture hall. In this regard, one participant remarked:

\begin{abstract}
We attended our workshops in a classroom in one of the schools in our circuit. We filled the classroom to capacity... it was very hot. So, it was very difficult to concentrate for a long time on what was being said. What made matters worse, because of the issues of space, the classroom did not have tables. As a result, it was very difficult to take the notes.... (Teacher L2-MAH).
\end{abstract}

The interview data revealed that there were inadequate laptops, data projectors and screens in all the sampled AOs to support the facilitation of programmes and activities related to teachers' CPD for curriculum change implementation. Additionally, several subject advisors claimed that they failed to provide school-based follow-up support and monitoring owing to the shortage of official means of transport. They revealed that the issue was around the bureaucratic processes to access such means of transport. Unfortunately, the problem of resource shortages may persist as none of the curriculum coordinators viewed the procurement of such resources as their responsibility. The problem of limited resources to support the delivery of CPD activities was also reported in related studies where it was attributed to non-prioritisation (Bubb and Earley, 2007), and the apartheid legacy (Brew in Lethoko, 2002; Rothman, 1996).

\title{
4.2.3 CPD managers' work overload
}

Data analysis suggests that CPD managers' workload is a significant impediment to discharging their role effectively. This applied more to members of SMTs than curriculum coordinators. The majority of HoDs and principals stressed that they were experiencing heavy teaching and administrative workloads related to on-going reforms of the education system. Consequently, they found it extremely difficult to devote time to teachers' CPD, especially with regard to curriculum change implementation. This is consistent with other findings (Mafora \& Phorabatho, 2011; Chisholm et al., 2005; Robins and Barnwell, 2002) which point to SMTs facing a lot of onerous administrative responsibilities and accountability that often erode their time for managing teachers' CPD for curriculum change implementation. Reflecting the ramifications of heavy workloads, one participant remarked:

\begin{abstract}
It is tough for us. You know there are so many things that battle for our attention. Often these things keep us away from classroom business. We are no longer just school principals. To mention but a few, some of us have heavy teaching workload, in addition to that we are expected to manage the Resolution 2, IQMS, learner feeding scheme, QLTC [Quality of Learning and Teaching Campaign] and rationalisation of schools at the same time as the ever-changing curriculum. We are always called for meetings at the $A O$ to discuss these things. So, where do we get time for teacher development in our schools? The department must come to the party (Principal L1-MOR).
\end{abstract}

The literature review is, however, devoid of plausible solutions to work overload of CPD managers that result from systemic reforms. The contention of this article is that CPD managers should delegate some of their tasks and responsibilities to capable subordinates. In this way, they may have time to focus on carrying out their role effectively.

\subsubsection{Teachers' change weariness}

The majority of participants mentioned change weariness on the part of teachers as another major hindrance to managing teachers' CPD for curriculum change. It emerged that the rapidity of curriculum reform and the resultant rushed implementations caused many teachers and some members of the SMTs from the selected schools to lose confidence in the certainty of what it was that they were supposed to do. In this regard, Teacher T1-DIT said: I no longer know what I should do or not do. Today is this, tomorrow is that, especially about assessment. In this regard, Parker (in Robins \& Barnwell, 2002), cautions that the goals of a new curriculum are not likely to be met if its implementers experience "systemic fatigue." Other possible causes for teachers' lack of interest in CPD activities include: the perception of CPD activities as a waste of time (McCarthy, 2006; Fullan, 2001); the lack of significant rewards (Day \& 
Sachs, 2004); and policy overload (Robins \& Barnwell, 2002). The researchers suggest that CPD managers may rekindle and sustain such teachers' interest in CPD for curriculum change implementation through the application of participative management approach and motivation.

\section{Conclusion}

The study examined the views and experiences of the participants concerning the role of curriculum coordinators and SMTs as managers of teachers' CPD for curriculum change implementation. Findings suggest that these managers were ineffective in discharging their role. Their effectiveness was constrained mainly by their lack of basic understanding of what constitutes their role and a number of systemic barriers and limitations. The state of affairs regarding CPD for curriculum change implementation suggests that affected managers require some form of purposeful support in order to carry out their duties and responsibilities effectively. To this end, the following measures are recommended to help address identified deficiencies:

- Provide appropriate targeted training to CPD managers

As CPD managers, curriculum coordinators and SMTs should be provided with short programmes that deal with particular aspects involved in managing the implementation of curriculum change in general and pertinent teachers' CPD in particular. These programmes should focus on fundamental management tasks like planning organising, leading and controlling. Attendance of these programmes can be incentivised by providing them in conjunction with accredited institutions or assigning them some credits towards formal qualifications. It could also be helpful if newly appointed curriculum coordinators and SMTs could be formally inducted and familiarized with the intricate demands of their jobs.

- Support the provision of CPD activities with relevant and adequate resources

Relevant divisions should expedite the procurement of resources like of laptops, data projectors and screens in all the sampled AOs to support the facilitation of CPD activities. Furthermore, the relevant sections that deal with official means of transport should prioritise the availability of such to the subject advisors so as to enhance the provision of school-based follow-up monitoring, mentoring and support. The conditions of the buildings of the makeshift CPD venues should be improved. This should be the responsibility of the NWED's Directorate of Physical Resources and Facilities Planning and Management Services. As a long term solution to the problems related with CPD accommodation, the NWED should consider the establishment of an Institute for Continuing Professional Teacher Development in each of its four districts. In this regard, the under-utilised buildings of former Colleges of Education in the Province may be helpful. These colleges have essential facilities like lecture halls, residences, and are easily accessible through public transport.

\section{References}

Blandford, S. 2000. Managing professional development in schools. New York: Routledge.

Bubb, S. \& Earley, P. 2007. Leading and managing continuing professional development. 2nd Edition. London: Paul Chapman Publishing.

Chisholm, L. Hoadley, U., Kivulu, M., Brookes, H., Prinsloo, C., Kgobe, A., Mosia, D., Narsee, H., \& Rule, S. 2005. Educator workload in South Africa. Cape Town: ELRC.

Coleman, M. 2005. Theories and practice of leadership: An introduction. In: Coleman, M. \& Earley, P. (Eds.) 2005. Leadership and management in education: cultures, change and context. New York: Oxford University Press: 6-25.

Creswell, J.W. 2009. Research design: Qualitative \& quantitative, and mixed approaches. $3^{\text {rd }}$ Edition. California: SAGE Publications.

Darling-Hammond, L. \& McLaughlin, M. W. 1995. Policies that support professional development in an era of reform. National College for School Leadership. 76 (8): 597-604.

Day, C. \& Sachs, J. (Eds.) 2004. International handbook on the continuing professional development of teachers. Berkshire: Open University Press.

Department of Basic Education, 2009. Report of the Task Team for the Review of the Implementation of the National Curriculum Statement. Pretoria: Department of Basic Education.

Department of Education. 2000. School Management Teams: Managing and Leading Schools. Pretoria: CTP Book Printers.

Department of Education 2001. Education in South Africa: Achievements since 1994. Pretoria. Government Printers.

Department of Education 2007. The National Policy Framework for Teacher Education and Development in South Africa: "More teachers; Better teachers". Pretoria: Department of Education.

Duthilleul, Y. 2005. Developing teachers' knowledge and skills: Policy trends in OECD countries. International Institute for Educational Planning. Seminar on Growth Strategies for Secondary Education in Asia, September 19-21.

Education Labour Relations Council 2003. Collective agreement number 8 of 2003: Integrated quality management system. Pretoria: 
ELRC.

Fullan, M. 2001. Leading in a culture of change. New York: John Wiley \& Sons, Incl.

Glover, D. \& Law, S. 2004. Managing professional development in education: issues in policy and practice. Oxion: Routledge-Falmer.

Ha, A.S.C., Lee, J.C.K., Chan, D.W.K. \& Sum, R.K.W. 2004. Teachers' perceptions of in-service teacher training to support curriculum change in Physical Education: The Hong Kong Experience Sport, Education and Society, Vol. 9(3): 421-438.

Hill, C.W.L., \& McShane, S.L. 2008. Principles of management. New York: McGraw-Hill//rwin.

Lemmer, E.M. \& Badenhorst, D.C. 1997. Introduction to education for South African teachers. Johannesburg: Juta \& Co. Ltd.

Lethoko, M.X. 2002. Teacher Professionalism and Motivation in a Culture of Teaching and Learning. D.Ed. Thesis. Pretoria: University of Pretoria.

Lethoo, T.S. 2011. The implementation of Developmental Appraisal in Matlosana Area Project Office schools. M.Ed. Dissertation, Pretoria : University of South Africa.

Lichtman, M. 2013. Qualitative research in education: A user's guide. $3^{\text {rd }}$ Edition. Thousand Oaks, California: SAGE Publications, Inc.

Lourens, J. 2012. Principles of general management. In: Nel, WP (Ed.). Management for engineers, technologists and scientists. $3^{\text {rd }}$ Edition. Cape Town: Juta \& Company: 15-38.

Lussier, R.N. 2009. Management fundamental: Concepts, applications and skills development. $4^{\text {th }}$ Edition. Mason: Cengage Learning.

Mafora, P. \& Phorabatho, T. 2011. Managing the implementation of curriculum change in Moretele secondary schools. In: Gouws, E, Dreyer, J, Dicker, A \& Wolhuter, C (Eds.). Beauty and the beast: Towards turning the tide in education. EASA conference proceedings, Sun City: January 10-13: 201-222.

Mafora, P. \& Phorabatho, T. 2013. Curriculum change implementation: Do secondary school principals manage the process? Anthropologist, 15(2): 117-124.

Mosoge, J. 2008. Talent development. Heystek, J, Nieman, R, Van Rooyen, J, Mosoge, J \& Bipath, K (Eds.). People leadership in education. Johannesburg: Heinemann Publishers (Pty) Ltd: 159-193.

McCarthy, E.H. 2006. When teachers take staff development personally. Principal Leadership, 71 (7): 45-49.

McMillan, J.H. \& Schumacher, S. 2010. Research in Education: Evidence-based inquiry. $7^{\text {th }}$ Edition. New Jersey: Pearson Education, Inc.

Mizell, H. 2010. Why professional development matters. Oxford: Learning Forward.

Mulkeen, A. Chapman, D.W., DeJaeghere, J.G, Leu, E. \& Bryner, K. 2005. Recruiting, retaining, and retraining secondary school teachers and principals in Sub-Saharan Africa. World Bank: Academy for Educational Development.

Munonde, L.C. 2007. Effective teaching and learning in secondary schools of the Thohoyandou District through continuous professional development programmes. M.Ed. Dissertation, Pretoria: University of South Africa.

Nkabinde, A.P. 2006. The role of staff development programmes in improving the performance of educators in Delmas secondary schools. M.Ed. Dissertation, Johannesburg: University of Johannesburg.

Ono, Y. \& Ferreira, J. 2004. A case study of continuing teacher professional development through lesson study in South Africa. South African Journal of Education, 30:59-74.

Opie, C. 2004. Research approaches. In: Opie, C (Ed.). Doing educational research: a guide to first time researchers. London: SAGE Publications Ltd: 72-94.

Phorabatho, T.A. 2010. Managing the implementation of the National Curriculum Statement in Moretele secondary schools. M.Ed. Dissertation, Pretoria: University of South Africa.

Prinsloo, I.J. 2008. Ensuring an effective staff. In: Van Deventer, I. \& Kruger, A.G. (Eds.). An educator's guide to school management skills. $5^{\text {th }}$ Impression. Pretoria: Van Schaik Publishers: 203-222.

Robbins, S. P. \& Barnwell, N. 2002. Organisation theory: Concepts and cases, $4^{\text {th }}$ Edition. Frenchs Forest: Prentice Hall.

Rothman, J.G. 1996. Efficient financial management as a means of maximizing available education resources. Unpublished M. Ed. Dissertation, Pretoria: University of Pretoria.

Sallis, E. 2008. Total quality management in education. New York: Taylor \& Francis Ltd.

Schulze, S. 2002. Research methodology: Study guide 4 for MEDEM3-5. Pretoria: University of South Africa.

Smit, P.J., Cronje, G.J., Brevis, T. \& Vrba, M.J. (Eds.) 2011. Management principles: A contemporary edition for Africa. $5^{\text {th }}$ Edition. Cape Town: Juta \& Company Ltd.

Steyn, G.M. 1999. Professional development: A key to school improvement. South African Journal of Education, 19 (3): $206-213$.

Steyn, G.M. 2010. Educators' perceptions of continuing professional development for teachers in South Africa: A qualitative study. Africa Education Review, 7(2):156-179.

Swanepoel, F. 2009. The administrator's duties. In: Badenhorst, CJ, Van Rooyen, AWP, Ferreira, EJ, Groenewald, D., Joubert, H.J., Marcus, J.S.F., Steenkamp, S. Swanepoel, F. Van den Berg, A. \& Van Heerden, A. Business and office administration: An outcomes-based approach. $2^{\text {nd }}$ Edition. Sandton: Heinemann Publishers (Pty) Ltd: 91-103.

Tanner, L.N. \& Rehage K.J. (Eds.) 1988. Critical issues in curriculum: Eighty-seventh yearbook of the national society for the study of education. Chicago: The University of Chicago Press.

Thwala, S.M. 2010. The Management of "No Fee" Schools in Mpumalanga: A case study of selected secondary schools. M.Ed. Dissertation, Pretoria: University of South Africa.

Tomlinson, H. 2004. Educational leadership: Personal growth for professional development. London: SAGE.

Tranter, S. 2006. Teaching and managing in schools: The next step. London: Pearson Education Limited.

Van Deventer, I. 2008a. Visualising and planning skills. In: Van Deventer, I \& Kruger, AG (Eds.). An educator's guide to school 
management skills. 5th Impression. Pretoria: Van Schaik Publishers: 78-94.

Van Deventer, I. 2008b. Education management in schools. In: Van Deventer, I \& Kruger, AG (Eds.): An educator's guide to school management skills. $5^{\text {th }}$ Impression. Pretoria: Van Schaik: 65-77.

Republic of South Africa. 1995. White Paper on Education and Training Notice 196. Cape Town: Department of Education Yin, R.K. 2009. Case Study Research: Design and Methods. $4^{\text {th }}$ Edition. Thousand Oaks, California: SAGE Publications, Inc. 